\title{
Contribution to the Calculation of Reinforced Concrete Circular Sections by Discrete Reinforcement
}

\author{
M. S. Kachi, Y. Bouafia, M. Saad, H. Dumontet, and S. Bouhrat
}

\begin{abstract}
The calculation of circular sections is not easy given the available reinforcements induces several unknowns in the equilibrium equations. The abacus of Davidovici, based on the principles of BAEL91 and EUROCODE2, assuming a uniform distribution of steel over the entire section, to determine the longitudinal reinforcement of these section bending made for this type of section limited in the case of a compressive axial load.

In this study we propose a method for calculating circular sections under any combined loads (N, M), using discrete reinforcement able to take into account both the compressive and tensile axial load. This method is based on the interaction curves of reinforced concrete sections that may generate the number of steel bars necessary for the point representative of the combination load $(\mathrm{N}, \mathrm{M})$ is within the strength domain of the section.
\end{abstract}

Index Terms-Reinforced concrete, circular section, nonlinear calculation, combined bending.

\section{NOMENCLATURE}

$A_{i}$ : Section of the bare $i$

$b_{i}$ : Base width of the layer $i$

$y_{a j}$ : Coordinate of the bare $j$

$D$ : Section diameter

$d$ : Wrapping steels,

$E_{a}$ : Steel Young modulus,

$E_{m}$ : Average concrete young modulus at a current point of the concrete

$f_{c}$ : Concrete compressive strength

$N 1$ : Applied axial load

$N$ : Internal axial load

$N_{a}$ : Internal Axial load due to the steel

$N_{b}$ : Internal Axial load due to the concrete

$N_{b b}$ : Number of steel bars

$\mathrm{Ne}$ : Number of trapeze,

$M 1$ : Applied Bending moment,

$M$ : Internal Bending moment,

$M_{a}$ : Internal bending moment due to to the steel

$M_{b}$ : Internal bending moment due to the concrete,

$y i$ : Coordinate of the base of the trapeze $i$,

$\gamma$. Angle between two successive bars,

$\phi a$ : Bars diameter,

$\delta \omega$ : The curvature,

$\delta u$ : The axial strain,

$\varepsilon$. Deformation,

$\sigma_{m}$ : Normal stress at a point of run the concrete section

$\Delta \sigma_{m}$ : Increase of the normal stresses on the concrete,

$\Delta \varepsilon_{m}$ : Increase of the longitudinal strain in the concrete,

osi: Stresses in the bar i ,

$\left\{\Delta \delta_{n}\right\}$ : Vector normal strains increase,

$\left[K_{s}\right]$ : Section stiffness matrix,

$\left\{\Delta F_{n}\right\}:$ Internal loads increase,

$\left\{\Delta F_{n b}\right\}$ : Concrete Internal loads increase vector,

Manuscript received March 16, 2013; revised July 11, 2013.

Mohand Said Kachi, Youcef Bouafia, Mohammed Saad and Salim bouhrat are with civil Engineering Department, Faculty of Engineering Construction, Mouloud Mammeri University,Tizi ouzou, Algeria (e-mail: kachi_ms@yahoo.fr, saad_moh_sli@yahoo.fr, salimbouhrat@yahoo.fr).
$\left\{F_{n b}\right\}:$ Concrete internal loads vector,

$\left\{F_{n a}\right\}$ : Steel internal loads vector,

$\{\Delta F a\}:$ Steel internal loads increase vector,

$\left[K_{1 a}\right]$ : Steel stiffness matrix

$\left[K_{1 b}\right]$ : Concrete stiffness matrix,

$\Delta \sigma_{a i}:$ Steel stresses increase,

$\Delta \varepsilon_{a i}:$ Steel strains increase,

$\left\langle\Delta \delta_{s}\right\rangle$ : Section strain increase,

\section{INTRODUCTION}

In general, the calculation of reinforced concrete regular sections is a well known problem and mastered [1]-[6]. In the particular case of circular or annular sections, analyzing the behavior of the section has been the subject of several studies we can mention [7]-[10], but the calculation of longitudinal reinforcement, is an complex problem. Taking into account the distribution of reinforcement in concrete, geometric characteristics are essentially the same in all directions. The arrangement of reinforcement induces several unknowns in the expression of the equilibrium equations, in particular, in the case of combined bending and axial load. In practice, the longitudinal reinforcement is calculated using abacus of Davidovici [11]. However, these principles are based on current regulations BAEL91 and EUROCODE2 [9], considering the steel uniformly distributed over the entire section of the concrete and in the case of a normal force of compression. The tensile normal load has not been considered.

We propose to construct a general method for calculating the circular sections using discrete reinforcement in the case of a combined bending and axial load regardless of what value of the bending moment and axial load.

This method is based on the nonlinear analysis of reinforced concrete sections. It can generate the number of steel bars required to balance a combination loads $(N, M)$ starting from the concrete section only then, adding the steel bars one by one until that point representative of the applied loads be into the strength domain of the section.

\section{GENERAL HYPOTHESIS}

The reinforced concrete section is circular subjected to combined bending and axial load. The study is conducted under the small strains hypothesis taking into account the non-linear elastic behavior of materials. Longitudinal strain is governed by the law of conservation of planar sections and it is assumed perfect adhesion between the steel and concrete. Considering these hypothesis, the longitudinal strain $\varepsilon$ is given by:

$$
\varepsilon=\delta u+y . \delta \omega
$$




\section{DisCRETIZATION OF THE CONCRETE SECTION}

The concrete section is assumed that a succession of trapezoidal layers (Fig. 1). Concrete layers are characterized by: the height hi, width bi, and the position of their base relative to a reference axis. The ordinate of the base of the trapezoid $\mathrm{j}$ can be calculated as follows:

$$
y_{j}=\left(D \cdot(j-1) / N_{e}\right)-D / 2
$$

The width of the trapeze $\mathrm{j}$ is given by:

$$
b_{j}=D \sin (\theta(j))
$$

where $\theta(j)=\operatorname{arcos} 2\left|y_{i}\right| / D$

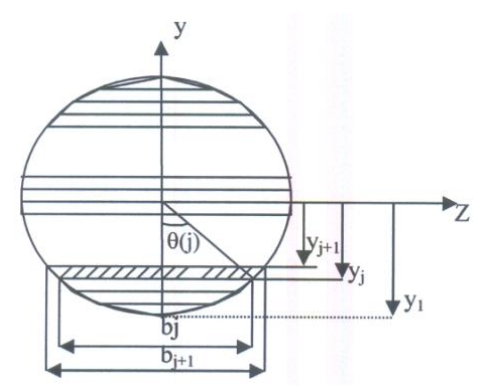

Fig. 1. Modélisation de la section de béton.

\section{DEFINITION OF THE POSITION OF THE BARS}

The position of the longitudinal reinforcements depends on the number $\mathrm{n}$, diameter has $\phi$ and the coating $d^{\prime}$ (Fig. 2). The position of a bar $i$ is defined relatively to a reference axis passing through the concrete center of gravity.

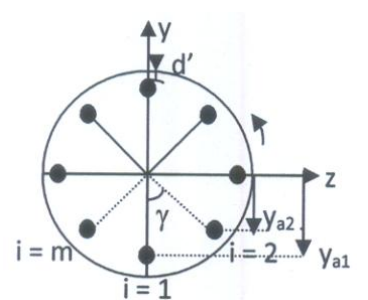

Fig. 2. Disposition of the bars in the section.

The ordinate of the bar number i is given by:

$$
\begin{aligned}
y_{a i} & =-\left(D / 2-d^{\prime}-\phi_{a} / 2\right) \cos ((i-1) \gamma) \\
\text { with } \quad \gamma & =2 \pi / N_{b t}
\end{aligned}
$$

\section{MATERIAL BEHAVIOR}

The behavior of materials is described by the behavior laws assumed by the Eurocode.

\section{CALCUlation OF InTERnAL LOADS}

\section{A. Solicitations Due to Concrete}

Internal normal loads due to concrete, can be written as a vector $\left\{F_{n b}\right\}$ :

$$
\left\{F_{n b}\right\}=\left[\begin{array}{l}
N_{b} \\
M_{b}
\end{array}\right]=\int_{\Sigma_{b}} \sigma_{m} \cdot\left[\begin{array}{l}
1 \\
y
\end{array}\right] \cdot d \Sigma_{b}
$$

Taking into account the relations 1 and 9, the increase of normal loads can be written in matrix form as follows:

$$
\left\{\Delta F_{n b}\right\}=\left[K_{1 b}\right] \cdot\left\{\Delta \delta_{n}\right\}
$$

with

$$
\left[K_{1 b}\right]=\int_{\Sigma_{b}} E_{m} \cdot\left[\begin{array}{cc}
1 & y \\
y & y^{2}
\end{array}\right] d \Sigma_{b}
$$

The increase of the normal stress $\Delta \sigma_{m}$ is relied to the increase of the longitudinal strains $\Delta \varepsilon_{m}$ by this relation:

$$
\Delta \sigma_{m}=E_{m} \cdot \Delta \varepsilon_{m}
$$

\section{B. Solicitations Due to the Reinforcement}

The normal loads due to the reinforcement are given by :

$$
\left\{F_{a n}\right\}=\left[\begin{array}{c}
N_{a} \\
M_{a}
\end{array}\right]=\sum_{i=1}^{n_{a}} \sigma_{a i} \cdot\left[\begin{array}{c}
1 \\
y_{a i}
\end{array}\right] A_{a i}
$$

The variation of the normal strains of the section produces a normal loads variation in the armatures. Taking into account the relations 1 and 10, we can write in matrix form:

$$
\begin{gathered}
\left\{\Delta F_{n a}\right\}=\left[K_{1 a}\right] \cdot\left\{\Delta \delta_{n}\right\} \\
{\left[K_{1 a}\right]=\sum E_{a} \cdot\left[\begin{array}{cc}
1 & y_{a i} \\
y_{a i} & y_{a i}^{2}
\end{array}\right] A_{a i}}
\end{gathered}
$$

The increase of the normal stress $\Delta \sigma$ is related to the increase of the normal strains $\Delta \varepsilon$ at the bar i by the relation:

$$
\Delta \sigma_{a i}=E_{a} \cdot \Delta \varepsilon_{a i}
$$

Neglecting the shear stresses due to reinforcement during deformation of the section, the relationship linking the loads increase with the strains increase in the armatures can be written in matrix form as follows:

$$
\left\{\Delta F_{n a}\right\}=\left[K_{1 a}\right] \cdot\left\{\Delta \delta_{n}\right\}
$$

The equilibrium of the section results in equal of applied loads increase and internal loads increase:

$$
\left\{\Delta F_{s n}\right\}=\left\{\Delta F_{n b}\right\}+\left\{\Delta F_{n a}\right\}
$$

The matrix linking applied loads increase and the strains increase in a reinforced concrete cross-section is:

$$
\begin{aligned}
& \left\{\Delta F_{s n}\right\}=\left[K_{s}\right] \cdot\left[\Delta \delta_{n}\right] \\
& {\left[K_{s}\right]=\left[K_{1 b}\right]+\left[K_{1 a}\right]}
\end{aligned}
$$

For the loads increase, the resolution in terms of the strains of the equation 16 is iterative. At the equilibrium of the section, the strains increase is given by:

$$
\begin{gathered}
\left\langle\Delta \delta_{n}\right\rangle=\left[S_{s}\right] \cdot\left\langle\Delta F_{s}\right\rangle \\
{\left[S_{s}\right]=\left[K_{s}\right]^{-1}}
\end{gathered}
$$




\section{APPLICATION to THE CALCULATION OF THE REINFORCEMENT}

The course of the boundary curve of the resistance domain of a circular or annular cross section (Fig. 3) shows that for a fixed value of $M$ in the interval [ab], we have two solutions in positive $N$ : what makes the search for value of normal force corresponding to point $\mathrm{P}(N, M)$ complex (nonuniqueness of the solution). But, for a normal load fixed the problem can be reduced to finding a unique solution in $M$ positive.

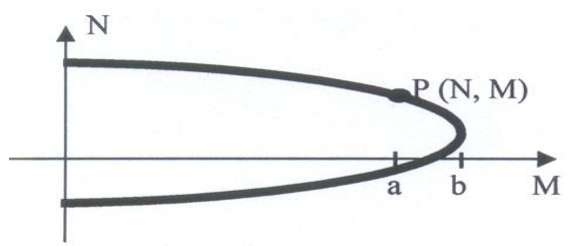

Fig. 3. Form of the interaction curve for a circular section.
We propose an iterative method able to generate the number of steel bars required for a circular or annular section to balance the forces acting couple $(N, M)$. This method is, for a normal force $N$ and fixed starting from a concrete sole, to add steel bars (one by one) to return to the point representative of torque forces acting on the inside of field strength of the section. The geometry of the section is refreshed at each time we add a bar. The principle of superposition can find the first section capable of resisting axial force $N$. This is considered a reference section at the beginning of calculation of the first bending moment greater than the moment soliciting and allows return precisely to the point representative of the torque soliciting effort into the resistance domain of the section. Finally, for the application of the method using a regulatory calculation, it is sufficient to adopt characteristics of materials (concrete and steel) allowed by the regulations. The Fig. 4 shows the general organization of the calculus method.

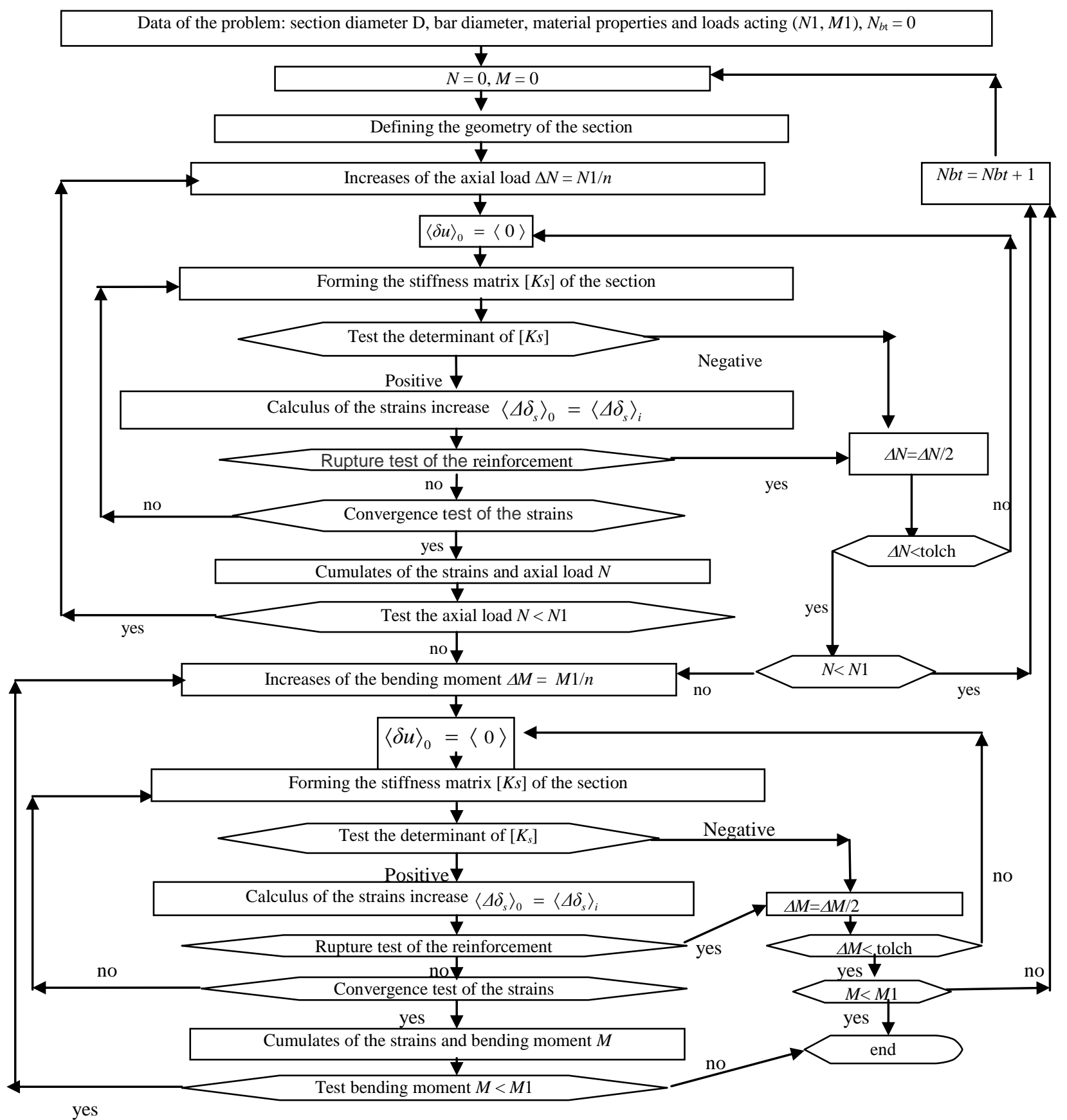

Fig. 4. General organization chart of the calculus method. 


\section{APPLICATION AND COMPARISON TO REGULATORY CALCULATIONS}

At first calculation the ultimate limit state is performed using the codes BAEL91 Eurocode 2 for a circular section subjected to pure bending and composed for diameters 70 and $100 \mathrm{~cm}$ with a report $d^{\prime} / D=0,1$. The elastic limit of steel is equal $F_{e} / \gamma_{s}=435 \mathrm{MPa}$., The compressive strength of concrete is taken equal to $f_{c} / \gamma_{b}=14.2 \mathrm{MPa}$ The calculation results compared with those given by the abacus of Davidovici (using BAEL91 and Eurocode2)

\section{A. Calculation of Simple Bending}

Fig. 5 and 6 show the comparison of the results obtained and those calculated using abacuses Davidovici on simple bending.

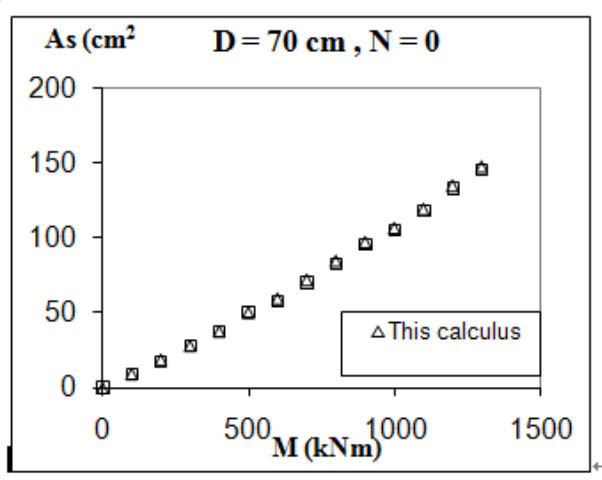

Fig. 5. Comparison of calculation results with those obtained with the abacus of Davidovici for a diameter of $70 \mathrm{~cm}$ in pure bending.

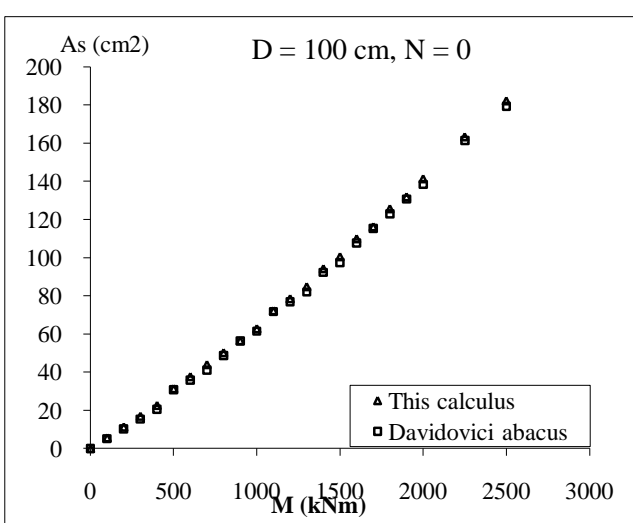

Fig. 6. Comparison of calculation results with those obtained with the abacus of Davidovici for a diameter of $100 \mathrm{~cm}$ in pure bending.

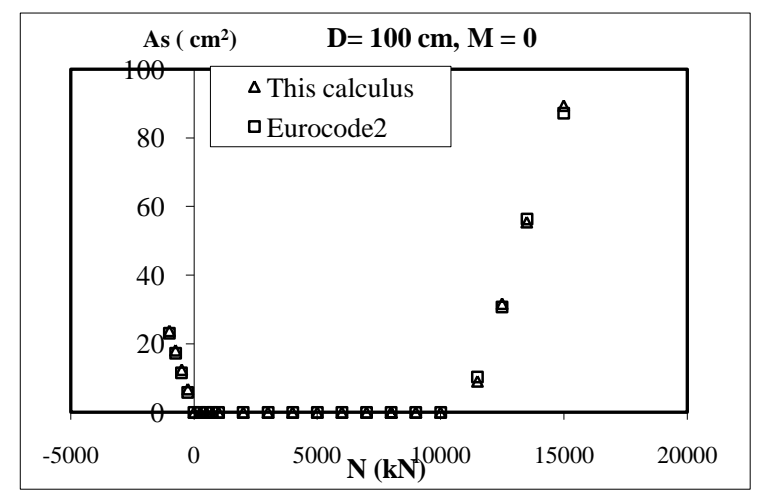

Fig. 7. Comparison of calculation results with those obtained by the eurocode 2 for a diameter of $100 \mathrm{~cm}$ on tension and compression.

The Fig. 7 and 8, present a comparison of the results of this calculation with those calculated according to the eurocode 2 on tension and compression simple.

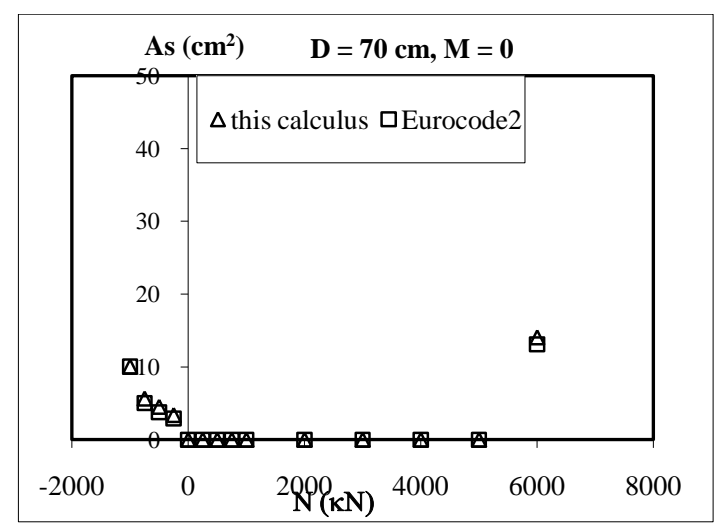

Fig. 8. Comparison of calculation results with those obtained by the eurocode 2 for a diameter of $70 \mathrm{~cm}$ on tension and compression.

\section{B. Calculation on Combined Bending and Axial Load}

The Fig. 9 and 10 show a comparison of results with those obtained from the abacuses of Davidovici for different diameters of the concrete section for elastic limit of steel equal to $500 \mathrm{MPa}$..

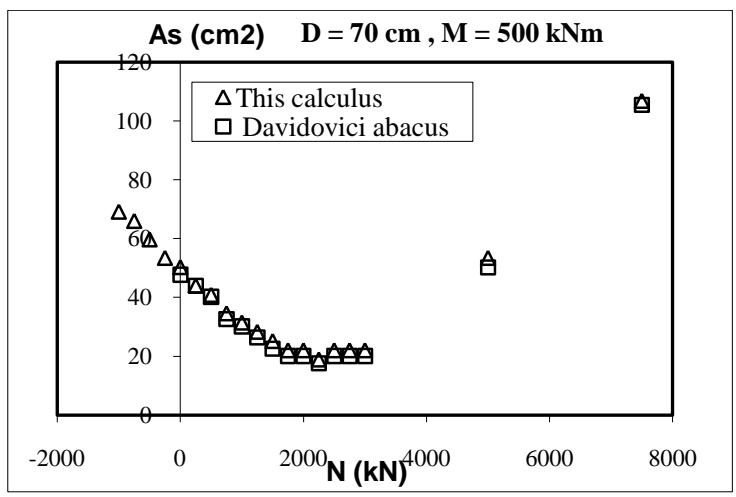

Fig. 9. Comparison of calculation results with those obtained with the abacuses of Davidovici for a diameter of $70 \mathrm{~cm}$ in combined bending and axial load.

In the case of sections subjected to compressive axial force, the comparison of the results of this calculation to the results obtained by applying the Eurocode 2 is satisfactory. The small difference observed is due to the fact that this calculation is not to find the exact section required to balance the combination of loads $(\mathrm{N}, \mathrm{M})$, but rather to find the first section that return the abscissa of the point $(\mathrm{M} \mathrm{N})$ ordered within the section strength domain while adding each time a steel bar (entire section of a frame) which is the case in practice.

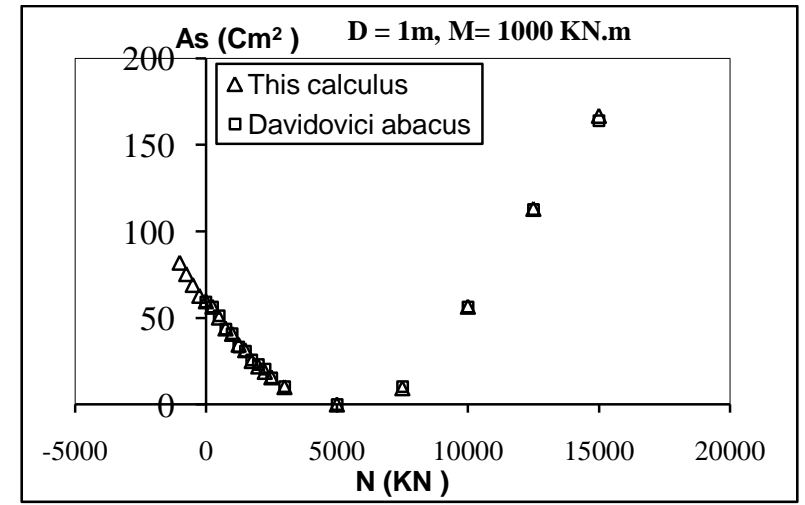

Fig. 10. Comparison of calculation results with those obtained with Davidovici abacus for $1 \mathrm{~m}$ of diameter in combined bending and axial load. 
In the case of a normal force of traction, the steel crosssection obtained by this calculation is consistent: in fact, nearly $M=0$, there is a continuity of the curve in the transition region from a tensile axial load to the compressive axial load. In addition, a value of $M=0$, we find without difficulty steel section given by calculation using Eurocode2.

\section{CONCLUSION}

This paper then proposes a simple method for calculating circular sections subjected to axial force (compression or tension) and bending moment. Calculation software is offered as a computational tool for the engineer. It offers many possibilities of calculation and verification of circular sections. It can generate the number of bars, diameter and their spacing for a couple of efforts $(N, M)$. Cases of solicitations are considered: simple compression, tension and bending composed Simple. It also serves as a tool for verifying the load capacity of a circular reinforced concrete section considering a regulatory calculation. Finally, opting for the real mechanical properties of the materials, it can simulate the real behavior of the sections in nonlinear elasticity to failure.

\section{REFERENCES}

[1] S. Rocca, N. Galati, and A. Nani, "Interaction diagram methodology for design of FRP confined reinforced concrete columns," Construction Building Materials, vol. 23, pp. 1508- 1520. 2009.

[2] M. Virlogeux and A. M'RAD, "Study of a beam section in nonlinear elasticity, application to reinforced concrete or prestressed composite section," Annals of ITBTP, no. 444, May 1986

[3] Y. Bouafia, "Numerical simulation of the average behavior until rupture of the beams, application to reinforced concrete, prestressed concrete and / or fiber reinforced concrete," DEA. Pierre et Marie Curie, Paris 6, France University in 1987.

[4] Y. Bouafia, M. S. Kachi, and F. Ghazi, "Prediction of rupture of reinforced concrete and fiber reinforced concrete circular sections, Mechanical Association Franco-Moroccan (AMFM)," in Proc. $4^{\text {th }}$ Edition Days of Technical Studies (JET2006) Marrakech-Morocco 2006.

[5] A. Grelat, "Nonlinear behavior and stability of reinforced concrete frames, "Annals of ITBTP, November 1978.

[6] M. S. Kachi, Y. Bouafia, P. Muller, and B. Fouré, "Modeling the behavior until rupture beams reinforced and prestressed concrete in nonlinear elasticity," in Proc. International Conf., "CMMSO8” 16, 17 and 18 Nov. Tizi Ouzou-Algeria, 2008.

[7] J. L. Bonet, M. H. F. M. Baros, and M. L. Romero, "Comparative study of analytical and numerical algorithms for designing reinforced concrete sections under biaxial bending," Computers and Structures, no. 84, pp. 2184-2193, 2006.

[8] M. Daunys and S. Rimovkis, "Analysis of circular cross-section element, loaded by static and cyclic elastic-plastic pure bending," International Journal of Fatigue, no. 28, pp. 211-222, 2006.

[9] E. Cosenza, C. Galasso, and G. Maddaloni, "A simplified method for flexural capacity assessment of circular RC cross-section," Engineering Structures, vol. 33, pp. 942-946, 2011.

[10] G. S. R. Davalath and M. K. S. Madugula, "Analysis/design of reinforced concrete circular cross-section," ACI Structural Journal, vol. 85 , no. 6 , pp. $617-623,1988$.
[11] V. Davidovici, "Form of reinforced concrete," Volume 1Calculations, Rules BAEL 91, Eurocode 2, Rules 92 seismic, Ed Monitor, 1996.

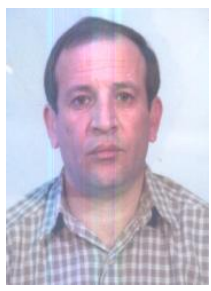

Mohand Said Kachi was born in May 3, 1966 in Algeria. He became a doctor in University of TiziOuzou in 2006.

He was a member of the laboratory LaMoMS Experimental and Numerical Modeling of Materials and Structures of Civil Engineering) Since 2002 and work as a professor at University "Mouloud Mammeri" of Tizi-Ouzou, 15000, Algeria and Lecturer from 1993 to 2012.

Prof. Kachi is invested in research themes: materials, experimentation, external prestressing, numerical modeling and nonlinear calculation of structures.

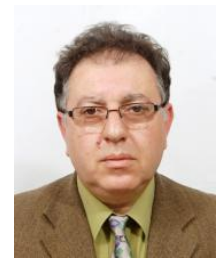

Youcef Bouafia was born in August 29, 1961 in Algeria. Since 2003 he is a professor at University "Mouloud Mammeri" of Tizi-Ouzou, 15000, Algeria and Lecturer from 1993 to 2003. And he became a doctor of $\mathrm{Ph} . \mathrm{D}$. Thesis of Central School, Paris in 1991.

$\mathrm{He}$ is a member of Laboratory LaMoMS (Experimental and Numerical Modeling of Materials and Structures of Civil Engineering), UMMTO and was the director of laboratory "LaMoMS" from 2002 to 2012 and the Head of Department of Civil Engineering from 1999 to 2002.

Prof. Bouafia is invested in research themes: materials and composites, experimentation, external prestressing, numerical modeling and nonlinear calculation of structuresProf. Bouafia is invested in research themes: materials and composites, experimentation, external prestressing, numerical modeling and nonlinear calculation of structures.

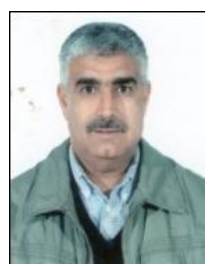

Mohammed Saad was born in January 19, 1954 in Algeria. He became a doctor since 2011 at University "Mouloud Mammeri" of Tizi-Ouzou. He is a member of the laboratory LaMoMS since 2002.

Dr. Saad is invested in research themes: materials, experimentation, external prestressing, numerical modeling and nonlinear calculation of structures.

Hélène Dumontet is a professor in University of UPMC in France.She is a member of Institu Jean Le Rond d'Alembert and works as an associate director of the team MISES Modeling and Engineering Solids.

Prof. Dumontet is invested in research themes: Micromechanics (multiscale approaches, damage, behavior of materials). Fracture Mechanics(brittle, ductile, variational approach, criteria boot Structures (optimization, vibration, stability, nonlinearities, anisotropy)

Bouhrat Salim was born in June 6, 1981 in Algeria. He became a magister since 2011 at University "Mouloud Mammeri" of Tizi-Ouzou in Algeria.

Mr Bouhrat is invested in research themes: nonlinear calculation of structures. 